\title{
Detection of phthalic acid esters in the packaging films of meat products
}

\author{
Soňa Bogdanovičová ${ }^{1}$, Alžbeta Jarošová ${ }^{\text {, Josef Kameník }}{ }^{2}$ \\ ${ }^{1}$ Mendel University, Faculty of Agronomy, Department of Food Technology, Brno, Czech Republic \\ ${ }^{2}$ University of Veterinary and Pharmaceutical Sciences Brno, Faculty of Veterinary Hygiene and Ecology, \\ Department of Meat Hygiene and Technology, Brno, Czech Republic
}

Received May 7, 2014

Accepted January 14, 2015

\begin{abstract}
The contents of di-n-butyl phthalate (DBP) and di-2-ethylhexyl phthalate (DEHP) were monitored in materials used for packaging films of meat products. A printed sample and a nonprinted sample were taken from each of the packaging films analysed, the sample area being $1 \mathrm{dm}^{2}$, to determine whether or not there is increased presence of phthalates in printed packaging films compared to non-printed packaging films, and to assess possible risks arising from their use. The determination of DBP and DEHP was conducted using high-performance liquid chromatography (HPLC) with the Zorbax Eclipse C8 column and UV detection at a wavelength of $224 \mathrm{~nm}$. Concentrations of phthalates ranged from 2.18 to $81.33 \mu \mathrm{g} \cdot \mathrm{dm}^{-2}$ in printed samples and from 2.25 to $69.88 \mu \mathrm{g} \cdot \mathrm{dm}^{-2}$ in those without printing. This study shows different contents of phthalates in printed and non-printed areas of packaging films. The printed area had in most cases a higher content of phthalates probably due to the content of the substances in the printing colours.
\end{abstract}

Phthalates, di-n-butyl phthalate, di-2-ethylhexyl phthalate, printed area, package

Phthalic acid esters (PAE) are organic lipophilic compounds that have become ubiquitous and major environmental contaminants due to their versatility and production (Koch et al. 2003). Phthalates are generally used as plasticisers (i.e. softeners) in the production of plastics (Ca o 2010). Since phthalate-based plasticisers are not firmly bonded by covalent bonding in the material, they can slowly release into the surrounding environment by volatilisation, leaching or migration (Xue et al. 2010).

Phthalates are substances that are easily soluble in fats, causing lipoperoxidation of lipoproteins, which underpins the development of atherosclerosis. Di-2-ethylhexyl phthalate migrates through PVC tubes into the blood depending on the concentration of blood fats. The reason for the migration of DEHP into the blood of patients treated with haemodialysis is, that the patients' blood is in direct contact with PVC tubes (Ramos and Martínes-Castelao 2008). Food can be contaminated either primarily during production, or secondarily as part of the subsequent processing and all types of handling. The materials with which food comes into contact are the main source of food contamination (CoreaTellez et al. 2008). Despite the fact that the use of PAE has been significantly limited in the production of packaging materials designed for food, it is important to pay attention to the content of contaminants in the printing colours (Wagner and Oehlmann 2009).

Any PAE content in a package need not indicate that the material is unsuitable for food packaging. There are barrier layers in certain types of packaging films that reduce or even stop the phthalate migration. Nonetheless, exceeding the permitted limit $\left(60 \mathrm{mg} \cdot \mathrm{kg}^{-1}\right.$ of the food or food stimulant; $10 \mathrm{mg} \cdot \mathrm{dm}^{-2}$ of the surface of the material) should be avoided in materials that are used for food packaging. Monitoring the phthalate content is necessary due to its negative effects on human health (Jarošová 2010).

This study aimed at monitoring phthalic acid esters in plastic packaging films of meat

Address for correspondence:

Ing. Soňa Bogdanovičová

Department of Food Technology

Faculty of Agronomy, Mendel University

Zemědělská 1/1665, 61300 Brno, Czech Republic
Phone: +420545133338

E-mail: sona.bogdanovicova@mendelu.cz

http://www.vfu.cz/acta-vet/actavet.htm 
products and determining whether or not the printed package is higher in phthalates compared to a non-printed area.

\section{Materials and Methods}

Packaging films of meat products were provided in cooperation with the Veterinary and Pharmaceutical University in Brno and analysed at the Department for Food Technology, Mendel University in Brno. A printed sample and a non-printed sample were taken from each of the packaging films, the sample area being $1 \mathrm{dm}^{2}$ in each case. With each of the samples analysed in duplicate, the analysis was carried out 88 times.

The samples were leached in a mixture of solvents, $n$-hexane:dichloromethane $(1: 1)$, for $72 \mathrm{~h}$ and then extracted $\times 3(60,30$, and $30 \mathrm{~min})$. The combined extraction fractions were filtered and evaporated using a rotary vacuum evaporator; then there was a final drying with nitrogen. Subsequently, the extract was transferred into vials using hexane $(5 \mathrm{ml})$ and centrifuged. The upper portion of the extract $(1.5 \mathrm{ml})$ was removed and fine-dried with nitrogen. Samples were centrifuged once again, the upper layer of the extract was removed (1.5 $\mathrm{ml})$ and fine-dried with nitrogen; then acetonitrile was added into each vial to make a volume of $1 \mathrm{ml}$. If an extract was coloured or turbid, it was purified using sulphuric acid. Phthalates were determined by the HPLC method using the column Zorbax Eclipse C8 and UV detection at a wavelength of $224 \mathrm{~nm}$. The quantity of the sample sprayed on the column was $10 \mu \mathrm{l}$. The resulting concentrations were computed based on the calibration curve using the AgilentChemstation software for LC and LC/MS systems. The range of the calibration curve was 1.06 to $106.00 \mu \mathrm{g} \cdot \mathrm{ml}^{-1}$ for DBP and 1.01 to $100.50 \mu \mathrm{g} \cdot \mathrm{ml}^{-1}$ for DEHP. The correlation coefficient was 0.9999 for both DBP and DEHP. The limit of detection was $0.05 \mu \mathrm{g} \cdot \mathrm{ml}^{-1}$ for DBP and $0.11 \mu \mathrm{g} \cdot \mathrm{ml}^{-1}$ for DEHP. In the final stage, the results were statistically processed by Student's $t$-test and then graphically processed using Microsoft Excel 2010.

\section{Results}

Concentrations of the monitored phthalates (DEHP and DBP) are specified in $\mu \mathrm{g} \cdot \mathrm{g}^{-1}$ of the original sample of the package and in $\mu \mathrm{g} \cdot \mathrm{dm}^{-2}$ of the sample area; they are listed in Table 1 . The phthalate contents found ranged from 2.18 to $81.33 \mu \mathrm{g} \cdot \mathrm{dm}^{-2}$ and from 4.33 to $139.93 \mu \mathrm{g} \cdot \mathrm{g}^{-1}$ for printed samples; for non-printed samples, they ranged from 2.25 to $69.88 \mu \mathrm{g} \cdot \mathrm{dm}^{-2}$, and from 1.89 to $126.46 \mu \mathrm{g} \cdot \mathrm{g}^{-1}$. For better understanding, mean concentrations of DBP and DEHP in different parts of packaging films of meat products specified in $\mu \mathrm{g} \cdot \mathrm{dm}^{-2}$ are displayed in Fig. 1.

\section{Discussion}

The main objective of the study was to determine whether or not printed packaging films of meat products involve greater presence of phthalates compared to non-printed materials. The study demonstrates the variability of the phthalate content in printed and non-printed areas of packaging films, when in most cases the concentration was higher in the printed area, probably due to the content of phthalates in the printing colours. Statistical evaluation showed no significant difference in terms of the DBP and DEHP content in packaging films without printing and printed packaging materials, while the calculated value of $\mathrm{t}_{21}=1.755$ was less than that in the table of quantiles of the Student's $t$-distribution, i.e. $\mathrm{t}_{21}(0.975)=$ 2.080 and $t_{21}(0.995)=2.831$.

Altogether 22 samples were analysed; 15 samples were established to have a higher content of DBP and DEHP in printed packaging films, whereas 7 samples were found to have a slightly higher content of phthalates monitored in the packaging films without printing. The variability of the phthalate content in printed and non-printed portions of the packaging films has also been demonstrated in studies by other authors (e.g. Xue et al. 2010).

Xue et al. (2010) analysed 13 printed materials that were in contact with foods. For comparative purposes, 4 blank samples were analysed that were not printed. The results showed an elevated content of phthalates in printed materials compared to those without printing. For this reason, 8 types of colours used for the printing of packaging films were tested to prove that they were the main source of contamination. The colours were confirmed to be the main source of the examined substances that could be a risk to food safety. 
Table 1. The mean DBP and DEHP concentrations in packages of meat products, specified in $\mu \mathrm{g} \cdot \mathrm{dm}^{-2} \mathrm{and} \mu \mathrm{g} \cdot \mathrm{g}^{-1}$.

\begin{tabular}{|c|c|c|c|c|c|c|c|}
\hline \multirow{2}{*}{$\begin{array}{l}\text { Sample } \\
\text { no. }\end{array}$} & \multicolumn{3}{|c|}{ Specification packaging } & \multicolumn{2}{|c|}{$\begin{array}{l}\text { DBP and DEHP } \\
\quad\left(\mu \mathrm{g} \cdot \mathrm{dm}^{-2}\right)\end{array}$} & \multicolumn{2}{|c|}{$\begin{array}{l}\text { DBP and DEHP } \\
\qquad\left(\mu \mathrm{g} \cdot \mathrm{g}^{-1}\right)\end{array}$} \\
\hline & Packaging composition & $\begin{array}{c}\text { Coating } \\
\text { thickness }(\mu \mathrm{m})\end{array}$ & OTR & $P$ & $\mathrm{NP}$ & $\mathrm{P}$ & NP \\
\hline 1 & BOPET//PE HB Peel & 62 & 5 & 2.93 & 2.6 & 3.95 & 1.89 \\
\hline 2 & BOPET//PE HB Peel & 52 & 5 & 48.97 & 11.76 & 54.46 & 10.63 \\
\hline 3 & $\mathrm{BOPP} / \mathrm{PE} / \mathrm{PA} / \mathrm{PE}$ & 110 & $50-140$ & 15.34 & 6.7 & 14.4 & 6.17 \\
\hline 4 & BOPET//PE HB Peel & 85 & $<4$ & 9.16 & 4.41 & 10.66 & 5.15 \\
\hline 5 & BOPET//PE HB Peel & 85 & $<4$ & 19.74 & 18.37 & 28.46 & 26.7 \\
\hline 6 & BOPET//PE HB Peel & 62 & 5 & 18.24 & 7.66 & 33.63 & 14.59 \\
\hline 7 & $\mathrm{BOPP} / \mathrm{PE} / \mathrm{PA} / \mathrm{PE}$ & 110 & $50-140$ & 13.46 & 11.01 & 24.44 & 19.84 \\
\hline 8 & $\mathrm{BOPP} / \mathrm{PE} / \mathrm{PA} / \mathrm{PE}$ & 110 & $50-140$ & 6.93 & 6.07 & 13 & 11.46 \\
\hline 9 & $\mathrm{BOPP} / \mathrm{PE} / \mathrm{PA} / \mathrm{PE}$ & 60 & 11 & 5.35 & 5.85 & 6.64 & 7.3 \\
\hline 10 & BOPET//PE HB Peel & 52 & 5 & 81.33 & 69.88 & 139.93 & 126.46 \\
\hline 11 & BOPET//PE HB Peel & 52 & 5 & 30.56 & 2.7 & 57.96 & 5.33 \\
\hline 12 & BOPET//PE HB Peel & 62 & 5 & 2.18 & 2.25 & 4.33 & 4.46 \\
\hline 13 & BOPET//PE HB Peel & 62 & 5 & 15.11 & 13.52 & 27.7 & 25.58 \\
\hline 14 & BOPET//PE HB Peel & 62 & 5 & 4.89 & 5.94 & 8.89 & 11.25 \\
\hline 15 & BOPP/PE/PA/PE & 60 & 11 & 5.48 & 6 & 5.55 & 6.59 \\
\hline 16 & $\mathrm{PA} / \mathrm{EVOH} / \mathrm{PA} / \mathrm{PE}$ & 60 & $<5$ & 23.18 & 14.7 & 27.89 & 19.13 \\
\hline 17 & $\mathrm{PA} / \mathrm{EVOH} / \mathrm{PA} / \mathrm{PE}$ & 60 & $<5$ & 23.81 & 17.62 & 27.75 & 20.12 \\
\hline 18 & BOPET//PE HB Peel & 52 & 5 & 30.39 & 23.07 & 56.08 & 42.56 \\
\hline 19 & $\mathrm{PA} / \mathrm{EVOH} / \mathrm{PA} / \mathrm{PE}$ & 60 & $<5$ & 23.09 & 32.83 & 40.37 & 60.57 \\
\hline 20 & BOPET//PE HB Peel & 85 & $<4$ & 10.59 & 26.3 & 19.4 & 48.34 \\
\hline 21 & BOPET//PE HB Peel & 85 & $<4$ & 11.54 & 23.16 & 19.96 & 43.53 \\
\hline 22 & BOPET//PE HB Peel & 62 & 5 & 11.21 & 6.56 & 10.16 & 9.19 \\
\hline
\end{tabular}

DBP - di-n-buthyl phthalate, DEHP - di-2-ethylhexyl phthalate, P - sample printed; NP - sample no printing, OTR - oxygen transmission rate $\left(\mathrm{cm}^{3} / \mathrm{m}^{2}\right.$ for $24 \mathrm{~h}$ at $\left.24{ }^{\circ} \mathrm{C}\right)$, BOPET - biaxially-oriented polyethylene terephthalate, PE polyethylen, BOPP - bi-axially oriented polypropylene, PA - polyamide, EVOH - ethylene vinyl alkohol, HB - high barrier

Studies by Shen (2005) and Fierens et al. (2012) also demonstrate the presence of phthalates in plastic packaging films that are in contact with foods. In the analysing presented, DEHP was the best represented phthalate. Shen (2005) determined the content of phthalates in plastic products, when he tested and analysed 25 kinds of samples including packaging bags, films, wrappers, boxes for use in microwave ovens, spoons, cups, and plates. Only a single sample out of the 25 examined did not contain traces of phthalates. The remainder of 24 samples contained at least three or more PAE. The most prevalent in the examined samples was DEHP. Also, the study of Fierens et al. (2012) has shown that DEHP is one of the most abundant phthalates in packaging materials. A study was dedicated to phthalate contamination on the Belgian market, analysing the presence of 8 phthalates in 400 samples of food packages. The phthalates involved were dimethyl phthalate (DMP), diethyl phthalate (DEP), diisobutyl phthalate (DIBP), di-nbutyl phthalate (DNBP), benzyl butyl phthalate (BBP), diethylhexyl phthalate (DEHP), dicyclohexyl phthalate (DCHP), and di-n-octyl phthalate (DNOP). The samples were split into 11 groups. The highest concentration for almost each of the groups was that of DEHP, the substance being followed by DIBP, DNBP, and BBP. 


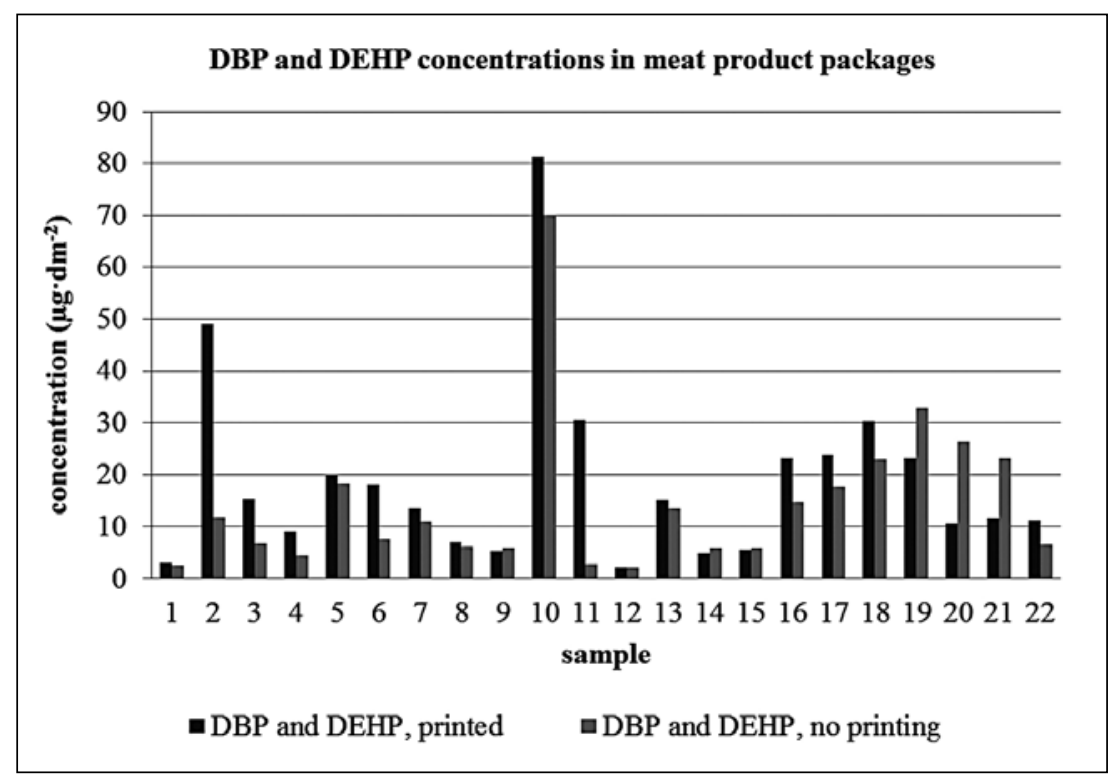

Fig 1. The mean DBP and DEHP concentrations in each part of packaging films of meat product, specified in $\mu \mathrm{g} \cdot \mathrm{dm}^{-2}$

Phthalate migration depends on numerous factors, such as the temperature and storage period, type of the packaging films, chemical composition of the packaged food, and others. Due to the lipophilic nature of the substances, phthalate migration is also subject to the fat content in the food. Migration DBP and DEHP is also dependent on the total phthalate content in the analysed samples. Studies by Cirillo et al. (2013), Zhang and Guo (2009), and Chen et al. (2008) affirm the fact that PAE migration is subject to the temperature and length of storage.

Cirillo et al. (2013) analysed ready meals wrapped in plastic containers and aluminium tableware provided to patients in hospitals in Italy. These were examined because of the likely DBP and DEHP migration from the package into the food. The study monitored the effects of temperature, storage period, and type of the packaging films on the migration process. The contents of phthalates in aluminium tableware were very low. A significantly higher amount of contaminants was observed in foodstuffs packaged in a plastic container, which indicates the migration of phthalic acid esters into the foods. The highest PAE values were recorded in the time slots when the food was maintained hot.

Zhang and Guo (2009) found that DEHP migration from a PVC film into meat increased with rising temperature and time, with the maximum being reached at $90{ }^{\circ} \mathrm{C}$ and $30 \mathrm{~min}$ of exposure $\left(1961.92 \mathrm{mg} \cdot \mathrm{kg}^{-1}\right.$, i.e. $\left.75.12 \mathrm{mg} \cdot \mathrm{dm}^{-2}\right)$. The aggregate migration limit $\left(60 \mathrm{mg} \cdot \mathrm{kg}^{-1}\right)$ was exceeded for all of the time and temperature combinations studied, except for that of $10{ }^{\circ} \mathrm{C}$ and $<41 \mathrm{~h}$, where migration was not observed. Chen et al. (2008) also demonstrated a significant migration of DEHP from the PVC film to the food after $3 \mathrm{~min}$ of heating in the microwave oven.

The phthalate content is necessary to monitor due to its adverse impact on human health. Heudorf et al. (2007) reported that the acute toxicity of phthalates is low but chronic toxicity caused by prolonged intake of low concentrations of these substances endangers 
human health world-wide. None of the phthalates are mutagenic or genotoxic, however, developmental and reproductive toxicity of those substances is likely even at concentrations that occur in natural settings.

Due to the health impact on humans as indicated above, the penetration of PAE into the environment must be controlled and the exposure reduced (Witas sek et al. 2011). One of the ways of progressive reduction of the risks of phthalates is to promote the substitution of toxic phthalates by other health-safe substances, e.g. citrates and benzoates, particularly in the production of materials used in agriculture, food, and health care.

The found PAE content in the packaging films of meat products complies with the limits set out in Commission Regulation (EU) No. 10/2011 which defines that plastics and plastic products may not release their components into food at an amount higher than $60 \mathrm{mg} \cdot \mathrm{kg}^{-1}$ of foodstuff or food simulant. The limit for aggregate migration per unit of area was set at $10 \mathrm{mg} \cdot \mathrm{dm}^{-2}$ of the surface of the material/product. The limit, however, includes other phthalates and many other substances which can be released from the material and thus migrate into the food. The highest concentration of DBP and DEHP found by the authors was $81.33 \mu \mathrm{g} \cdot \mathrm{dm}^{-2}$ and $139.93 \mu \mathrm{g} \cdot \mathrm{g}^{-1}$ as established for the printed packaging films. Therefore, we may conclude that the concentrations of DBP and DEHP found in the monitored packaging films do not constitute a serious health risk for the consumer.

\section{Acknowledgements}

This study was supported by the Internal Grant Agency, Faculty of Agronomy, Mendel University in Brno, project IP 10/2014.

\section{References}

Cao XL 2010: Phthalate esters in foods: sources, occurrence, and analytical methods. Compr Rev Food Sci Food Saf 9: 21-43

Chen ML, Chen JS, Tang CL, Mao IF 2008: The internal exposure of Taiwanese to phthalate-An evidence of intensive use of plastic materials. J Enviro Int 34: 79-85

Cirillo T, Fasano E, Esposito E, DelPrete E, Cocchieri RA 2013: Study on the influence of temperature, storage time and packaging type on di-n-butylphthalate and di(2-ethylhexyl) phthalate release into packed meals. Food Addit Contam, Part A 30: 403-411

Commission Regulation No. 2011/10/EC of the Commisssion of the European Communities of 14 January 2011 relating to plastic materials and articles intended to come into contact with food stuffs. OJ L 12, 13 March 2014, pp. 4-12

Corea-Tellez KS, Bustamante-Montes P, Garcia-Fabila M, Hernandez-Valero MA, Vazquez-Moreno F 2008 : Estimated risks of water and saliva contamination by phthalate diffusion from plasticized polyvinyl chloride. Environ Health 71: 34-39

Fierens T, Servaes K, Van Holderbeke M, Geerts L, De Henauw S, Sioen I, Vanermen G 2012: Analysis of phthalates in food products and packaging materials sold on the Belgian market. Food ChemToxicol 50: 25752583

Heudorf U, Mersch-Sundermann V, Angerer E 2007: Phthalates: toxicology and exposure. Int J Hyg Environ Health 210: 623-634

Jarošová A 2010: Assessing the occurrence of phthalates (1992-2009) in packaging materials, plastics, medical supplies and the blood of patients in feed and food and tissues of slaughteranimals and fish (in Czech). J Acta Univ Agric Silvic Mendelianae Brun 58: 263-268

Koch HM, Drexler H, Angerer J 2003: An estimation of the dailyintake of di(2-ethylhexyl) phthalate (DEHP) and other phthalates in the general population. Int J Hyg Environ Health 206: 77-83

Ramos R, Martínez-Castelao A 2008: Lipoperoxidation and hemodialysis. MetabClin Exp 57: 1369-1374

Shen H 2005: Simultaneous screening and determination eight phthalates in plastic products for food use by sonication-assistedextraction/GC-MS methods. J Talanta 66: 734-739

Wagner M, Oehlmann J 2009: Endocrine disruptors in bottled mineral water: total extrogenic burden and migration from plastic bottles. Environ Sci Pollut Res 16: 278-286

Wittassek M, Koch HM, Angerer J, Brüning T 2011: Assessing exposure to phthalates-the human biomonitoring approach. Mol Nutr Food Res 55: 7-31

Xue MG, Wang SF, Huang CX, Xia NN 2010: The analysis of organic contaminants in printing paper food packaging materials. In: Proceedings of the 17th IAPRI World Conference on packaging. Scientific Research Publishing, USA, pp. 360-363 
Zhang S, Guo K 2009: Migration amount of di-2-ethylhexyl phthalatefrom food-grade PVC film into meat at three temperatures. J Agric Eng Res 25: 291-293 